\title{
Building Enthusiasm and Overcoming 'Fear': Engaging with Christian Leaders in an Age of Science
}

\author{
Lydia Reid
}

Junior Research Fellow, St. John's College, Durham University, UK.

\section{Abstract}

In popular culture the relationship between science and religion has often been portrayed as one of conflict. The impact of the conflict thesis can be observed in church leaders' hesitancy in talking about science and religion in the public domain. It was this finding that led Revd Professor David Wilkinson (cosmologist and theologian) and Professor Tom McLeish (physicist and Anglican lay reader) to form the project 'Equipping Christian Leadership in an Age of Science' funded by The Templeton World Charity Foundation. The data presented in this article (collected during 2015-2018) is derived from two discreet pieces of research. The first consisting of a survey of over 1,000 church leaders and interviews with 20 senior church leaders and, the second, with a strategic focus on ministerial training comprised of 12 interviews with church educators. This paper reflects on the findings from both pieces of research - covering topics such as church leaders' enthusiasm towards science, how church leaders view the relationship between science and religion and the role of compartmentalisation in ministerial training. The article is unique in providing sociological analysis on the relevant data and including a personal reflection by David Wilkinson - the project's director - on the implications of the research for ministerial training and science.

\section{Funding and Institutional Affiliation}

The research was funded by The Templeton World Charity Foundation between 2015-2019 and carried out on behalf of 'Equipping Christian Leadership in an Age of Science' based at St. John's College, Durham University.

\section{Introduction}

One does not have to look too far to find examples of the 'conflict thesis' playing out in popular culture with examples being found in new atheist literature, comments made by 
comedians (Ricky Gervais and Stephen Fry) and tv programmes/documentaries (Big Bang Theory and The Root of all Evil). The conflict thesis (the idea that science and religion are fundamentally opposed to each other) can easily be replicated in the media by constructing debates between scientists who are anti-religious and preachers who are anti-evolution. Given the latter, it is not too surprising that when I asked church leaders the question: 'would you be willing to talk about science-based issues in the public domain?' most of the nonscientist senior church leaders I interviewed responded in one of the following ways, they:
a) Declined the invitation
b) Asked for further clarification on the issues being discussed
c) Delegated the task to a known 'expert'

When probed further, their hesitation about taking part was directly linked to not wanting to appear uninformed or inadvertently participating in a media platform that has been purposely set up to convey conflict between science and religion. Both answers a) and c) are indicative of a perception of science that is both highly specialised and impenetrable to the lay person. Indeed, the Chief Executive of the British Science Association, Katherine Mathieson also alluded to this when she observed that '[S]cience needs to be taken out of its cultural ghetto... [I]'s seen as the realm of professionals and experts' (Mathieson, 2017). Mathieson adds that this is more prevalent in science than other academic/societal spheres such as business, arts, politics or sports. Putting aside Mathieson's comments for one moment, now let us consider how the relationship between science and religion is presented in the public domain in the UK.

Despite the conflict thesis persisting in popular discourse, there are beginning to be small ripples of change, with people presenting a more nuanced account of science and religion in the media. For example, Brian Cox has recently spoken out about the limits of knowledge in science and his own personal agnosticism ('Atheism vs God' in Russell Brand's Under the Skin podcast). In 2016 Cox attended a diocesan clergy day in Leeds where he spoke about the need for science to engage with other disciplines, such as: theology, philosophy, art and music - in order to make sense of human 'meaning'. Cox also acknowledges the religious origins of science and is more receptive than, say, Richard Dawkins, in fostering constructive dialogue between science and religion (https:/www.youtube.com/watch? $v=9$ eG-XDPXS8). Radio 4 has also recently commissioned a series called 'The Secret History of Science and Religion' in conjunction with the think-tank Theos. This series aims to 
address the myths around the history of science and religion (https://www.youtube.com/watch?v=Dg82jr583ml). It remains to be seen whether this more nuanced approach to science and religion gains traction in wider culture or whether it remains an under-reported position in the media.

The observation referenced at the beginning of this article emerged from the research carried out on the 'Equipping Christian Leadership in an Age of Science' (ECLAS) project. The project is funded by the Templeton World Charity Foundation and headed by Revd Professor David Wilkinson (cosmologist and theologian) and Professor Tom McLeish (Anglican lay reader and physicist). Its purpose, as highlighted in the project's title, has been to raise awareness of science-based issues in the church community and to facilitate and promote greater dialogue between academic scientists and church leaders. I will provide more detail on the project over the next few pages, however, for now, I want to focus on the purpose of this paper which is to share the findings from two stages of the ECLAS research.

The first stage consisted of a nationwide survey of over 1,000 UK church leaders and interviews with over 20 senior church leaders. The second stage, smaller in nature, included interviews with 12 church educators on the theme of artificial intelligence and ministerial training. In both phases of the research I found that although there is an enthusiasm and interest in science among church leaders and educators, this does not translate into confidence in talking about science in the public domain. Alongside the presentation of the aforementioned findings there will also be a reflection provided by ECLAS Project Director David Wilkinson. He operates in the unique position of a "boundary pioneer", navigating the academic terrain of science and theology (Ecklund, 2010: 46). In his account he will encourage clergy, educators and readers alike to reflect on what theological and scientific engagement might look like, as well as offering some practical next steps.

\section{The Project - Equipping Christian Leadership in An Age of Science}

'Equipping Christian Leadership in An Age of Science' was founded by Wilkinson and McLeish as a response to the perceived persistence of the conflict thesis in the public domain and the perception of church leaders as fearful or hesitant in talking about science and religion. During its preliminary year in 2014 the project's then researcher, Dr Rebecca Bouveng, found that there was indeed a lack of confidence in talking about science among church leaders and, further still, that this lack of confidence extended beyond talking in the 
public domain, and into not wanting to be interviewed on science at all (an issue I shall return to later in the paper) (Bouveng, 2015: 101). In 2015 Wilkinson and McLeish (in partnership with Church of England stakeholders) secured further funding through the Templeton World Charity Foundation for a three year project aimed at facilitating the dialogue between science and Christianity. The project is unique in bringing together social scientists, natural scientists, theologians and senior staff from the Church of England. Alongside the research into clergy attitudes to science, which I mentioned earlier, the ECLAS project also has a number of other foci:

- To provide theological training resources on science for ordinands

- To fund 'Scientists in Congregations' schemes (bringing together clergy and scientists from within the congregation to formulate events and research on science and religion)

- To host conferences on key scientific areas in conjunction with the academic scientists based at Durham University (covering topics such as cosmology, the environment, evolution, neuroscience, end of life and artificial intelligence)

- To provide expert advice/support on complex issues (achieved through having a presence in the Mission and Public Affairs Division of the Archbishops' Council, Church House)

After completion of the ECLAS project in 2018, the team secured further funding for one year to scope research into artificial intelligence $(\mathrm{Al})$, technology and ministerial training. During this year, 12 interviews were carried out with church educators to assess their views on the inclusion of science (and, specifically Al) in ministerial training. The results of which are included in this paper.

\section{Existing Research on Science and Religion}

Social scientific research into science and religion is an expanding area. In the US it remains a popular topic of exploration and it is also gaining momentum in the UK with a diversity of themes being addressed, such as: science and non-religion (Lee, 2019; Kind, 2019), science and Islam (Unsworth, 2019; Carlisle et al. 2019) public perceptions of science (Baker 2012; Pew Research Centre Survey 2014; Hill 2015); churchgoers' views on science (Evans 2011); university students' views on religion and science (Ingram and Nelson 2006; 
Hill 2011); academic scientists' views on religion (Ecklund et al. 2011; Ecklund 2012); STEM career choices and religion (Scheitle and Ecklund 2017) and creationism and social networks (Hill 2014). In the UK the Science and Religion Exploring the Spectrum (SRES) team are leading the way in this area. In 2014-2017 Professor Fern Elsdon-Baker and her interdisciplinary team conducted a major national survey into public attitudes towards science using samples from the UK and Canada. The project has since received further funding from the Templeton Religion Trust for an interdisciplinary global study on religious perceptions of evolution.

There has also been notable interest in views on evolution (using survey methods) with a number of polls being carried out in the UK over the last ten years: BBC and Ipsos Mori ('The Origins of Human Life' - 2006), UK Theos ('Faith and Darwin' - 2008), International British Council ('Darwin Now' - 2009), YouGov (carried out by Unsworth, 2014), SRES project and YouGov (2017). One of the key issues in carrying out research in science and religion has been the extent to which surveys inadvertently 'force' particular positions; be it in the explicit wording or implicit assumptions behind the questions and corresponding answers. The starkest examples of this can be found in questions relating to the interpretation of Genesis, the age of the earth, evolution and, as shown by my research, the relationship between science and religion.

Research specifically on church leaders and science, however, is scarcer and where such work has taken place, generally the sample sizes have been small. Of those studies, the themes of interest have generally been on the connection between personal faith and science (Bouveng and Wilkinson, 2016), the relationship between science and religion (Gregory, 2017), views on evolution and creationism (Colburn and Henriques, 2006) and the implications of science and religion in education (Dickerson et al, 2008). For the ECLAS research there was a desire to upscale the sample size so that a 'snapshot' could be provided on the way in which UK church leaders make sense of and understand science. Similarly to the themes mentioned above, the research was centred on how church leaders understand science and Christianity, their views on key science issues (evolution included), the extent to which science issues emerge (or not) in a church context, and suggestions on including science in ministerial training.

To date, there has been no research exploring the aforementioned issues using a large sample size and a combination of qualitative and quantitative methodologies. The closest 
study in terms of size was the Barna Survey commissioned in 2012 by BioLogos (a Christian advocacy group with a special interest in science and religion) which conducted 743 telephone interviews with pastors from across the US and from all Christian denominations. In their study they found a diversity of views held in relation to human origins but categorised pastors into the following typology:

\footnotetext{
'Young earth creationism: core and leaning'

'Progressive creationism: core and leaning'

'Theistic evolution: core and leaning'

'Uncertain'
}

Of the 743 pastors surveyed, $54 \%$ were described as 'young earth creationists' with $35 \%$ in the 'leaning' category and 19\% in the 'core'. As I pointed out earlier in the paper, survey data on responses to evolution and creation are notoriously difficult to collect and subsequently analyse. Each survey has its own measures, as indicated by the Barna survey, and its inclusion of 'core' and 'leaning' responses. Making comparisons between data sets is difficult as there are no uniform measures, and other variables (such as sample size and Christian affiliation) can also affect the result. For example, in Dickerson et al.'s US study of 63 Methodist ministers, they found that most of their participants accepted evolution and "only $20 \%$ of the 56 participants [...] considered evolutionary theory to be 'lacking and unsatisfactory' and 'difficult to reconcile with faith in a creating God'" (Dickerson et al. 2008: 371). The remaining participants viewed evolution as "God's hand at work" (loc.cit.). Interestingly, Dickerson et al. asked their participants to complete a geological timeline plotting the following events in order of occurrence: dinosaurs, formation of the Earth, people, birth of Jesus Christ, formation of the universe, first appearance of bacteria on Earth. The inclusion of the geological timeline was novel and it also highlighted the complexity of asking questions in this area as answers to both questions were not always consistent. For example, Dickerson et al. noted:

...[W]ith the geologic timescale, we could not identify trends relating acceptance of scientific views and a particular relationship between science and religious faith. For example, of the $20 \%$ who did not accept evolution, only four held Religion Trumps Science views (e.g. 'They agree but faith (Bible) is more reliable'), while the other seven held Independence (e.g. 'Science describes 'what' and 'how', faith is 
concerned with 'why') or Integration (e.g. 'They relate and complement each other') views (Dickerson et al. 2008: 371).

The assumption in the extract above is that if someone does not accept evolution then they ought to fall into the 'religion trumps science' group. However both my research, and the work of Elsdon-Baker (2015), and Unsworth and Voas (2018), have shown that views in this area are not always consistent with a normative position. For example Harrold et al. found that in American society "science is a powerful source of authority [...] and creationists, like most Americans, tend generally to accept scientific knowledge, unless it threatens their worldview" (Harrold et al., 2004: 72). Harold et al. point out that although creationism is often seen as an "anti-intellectual" movement, it is one which includes plenty of what he refers to as "knowledge workers": scientists, technicians and engineers. These workers all want to prove scientifically that evolution is "pernicious" and "incorrect" (loc.cit.). Moreover, members of this movement will present scientific data to support creation putting them in the unusual position of wanting to reject mainstream scientific views on evolution, whilst also simultaneously using the "authenticating symbols" of science to support their creationist arguments (loc.cit). Moreover, as Elsdon-Baker notes, denial of or uncertainty towards evolution cannot be 'neatly packaged as scientific knowledge deficit' (Elsdon-Baker, 2015: 425), nor does it necessarily mean that the respondent is anti-science.

One of the key threads running through the findings laid out above is the assumption on the part of the researcher that participants must hold a) logically consistent views and b) normative views but as Jonathan Hill reminds us:

...those with academic positions....are incentivized to develop logically consistent worldviews and intellectual systems. Holding multiple, sometimes logically inconsistent, belief propositions is not a problem for most people. This isn't to say that no one ever attempts to make beliefs congruent; it is simply an acknowledgement that there is a level of messiness and incoherence in public opinion (Hill, 2015).

Similarly to Dickerson et al. (2008) Colburn and Henriques' (2006) research on clergy acknowledged that the creationist community were not unified in their views and they also used a typological system to capture participant views on creation:

'Young earth creationism - literalist and progressive' 
'Old earth creationism - literalist and progressive'

'Intelligent design'

(Colburn and Henriques, 2008: 421-422)

Colburn and Henriques identified a lack of internal consistency about understanding the periods of time associated with 'young earth creationism'; with some participants referring to a 'day' as capturing thousands of years which is arguably more consistent with 'old earth creationism' (Ibid., 421). Moreover, they also found that 'old earth creationism' came close to accepting a literal account of Genesis. Interestingly, unlike in Dickerson et al's research, Colburn and Henriques found that none of their participants selected the 'religion trumps science' group.

\section{Methodology}

As Bouveng and Wilkinson found in their preliminary research, one of the major barriers of carrying out fieldwork with church leaders on science is their reluctance (particularly if they are from a non-science background) to be interviewed or surveyed on the topic. Existing work on issues around recruitment in academic research have tended to focus on accessing 'hidden' or 'hard to reach' groups (Ellard-Grey et al. 2015, Rockliffe et al. 2018). In addition, Gilliat-Rae reflected on her experience of 'frustrated access' when trying to recruit participants from an Islamic college. Some of the discussion here is framed within the context of 'insiders' and 'outsiders' with researchers typically being the 'outsider' to their target sample group. To a certain extent this was also the case with my research on church leaders (given that I was not known to the participants or broader church community); but I would also argue that the wider context of how science and religion is perceived was also playing out here (see Reid, 2019: 79 for an anecdotal example of this). In the case of the former (not being known to the sample group), I enlisted the help of 'gatekeepers' to help establish 'trust' between myself and the participants (Lewis-Beck et al. 2003: 3). This was particularly useful when recruiting Church of England bishops (who were the most difficult group to secure) often due to their busy schedules. However, after establishing the help of gatekeepers within the Mission and Public Affairs Division of the Archbishops' Council, I was then able to secure a further four interviews with Church of England bishops. 
Having already highlighted some of the difficulties in recruiting participants for the research, there was a further layer of complexity in that those who did offer to be included in the research tended to exhibit one or more of the following characteristics:
a) Were from a 'science background' themselves
b) Knew someone who was from a science background; or
c) Had a strong interest in science issues

It is important to remember that the research participants were 'self-selecting' and, as Bouveng and Wilkinson (2016: 101-102) rightly point out, skewed towards 'a sample of leaders who themselves do not fear engagement with science'. Similarly, Dickerson et al (2008) found this phenomenon in their sample of 63 United Methodist Ministers with just under half having a degree or higher in science and with $94 \%$ rating their science knowledge as 'good' or 'very good'. Dickerson et al stated that the latter percentage was 'troubling' since it may indicate an 'overconfidence in their understandings' (Dickerson et al, 2008: 368). Out of the 20 participants I interviewed, 5 were from a 'science background' (just under a third). This outcome was better than I had originally envisaged, however, I would argue that the remaining interviewees typically did have an interest in science (a variable harder to quantify than educational background).

The interview and survey participants included in the first phase of research were from a range of Christian denominations: Methodist, Baptist, United Reformed Church (URC), Pentecostal and Catholic clergy. However, due to the difficulty in recruiting participants, the sample was skewed primarily towards Anglicans. A breakdown of the participants for the survey and interviews from the first phase of research can be found below:

\section{Table 1: Christian Affiliation of Survey and Interview Sample (from first phase of ECLAS research)}

\begin{tabular}{|l|l|l|l|l|l|l|l|}
\hline Sample & $\begin{array}{l}\text { C } \\
\text { of } \\
\text { E }\end{array}$ & Catholic & Baptist & URC & Methodist & Pentecostal & Total \\
\hline Survey & 921 & 9 & 49 & 36 & 46 & 39 & 1100 \\
\hline Interview & 9 & 2 & 3 & 3 & 2 & 1 & 20 \\
\hline
\end{tabular}


In the case of the second phase of research most of the participants were from the Church of England and this was intentional since the Church of England is a key stakeholder in the project, and ECLAS had already begun to contribute to the Church's Common Awards programme which is used in ordination training. The background of those interviewees were as follows:

Table 2: Occupations for Interviewees (from second Phase of ECLAS research)

\begin{tabular}{|c|c|c|c|}
\hline $\begin{array}{l}\text { Theological } \\
\text { Principals }\end{array}$ & $\begin{array}{l}\text { Directors of } \\
\text { Ministry }\end{array}$ & $\begin{array}{l}\text { Diocesan } \\
\text { Trainers (inc } \\
\text { LLM and } \\
\text { readers) }\end{array}$ & $\begin{array}{l}\text { Strategic Figures } \\
\text { (with science } \\
\text { interests) }\end{array}$ \\
\hline 3 & 3 & 3 & 3 \\
\hline
\end{tabular}

Unlike in the previous research where I openly recruited participants to talk about 'science', in the second phase I advertised under the heading 'ministerial training in a modern world'. This was to avoid some of the difficulties I encountered when using the word 'science' which seem to put off a number of church leaders. As a result of omitting the word 'science' I was able to recruit participants working in a theological education more easily. However, I still found a tendency towards having an interest in science among those I interviewed - a point I will expand on in the next few pages.

\section{Research into clergy attitudes to science - Findings}

\subsection{Enthusiasm, interest and engagement}

One of the key findings to emerge from the survey was that $91 \%$ of church leaders were having conversations about science with $61 \%$ of those having had these conversations over five times a year. Popular topics of discussion featured were: climate change, evolution and origins of the universe. When asked what prompted the conversation $30 \%$ cited 'personal interest' and this trend was consistent across Christian denominations. Further evidence of personal interest was also observed in the finding that $85 \%$ of church leaders had researched, read or watched a TV programme on science in the last year. This level of enthusiasm towards science was encouraging from the perspective of the ECLAS project as it meant that there was a potential appetite for providing resourcing on the area beyond 
clergy from a science background. As I pointed out earlier, enthusiasm towards science was also found in the Barna survey where $89 \%$ of clergy (regardless of their views on evolution) felt that addressing science issues in their local community was somewhat $(51 \%)$ or very (21\%) urgent (Barna, 2012). Given the level of enthusiasm felt towards science among clergy, it is perhaps somewhat surprising that this did not translate into having confidence in talking about science in the public domain. For example, three of the senior church leaders I interviewed responded to the question 'would you take part in a local radio interview on science and Christianity' with the following: 'l'd run a mile!' (Participant 19, C of E Bishop), 'I'd clench buttocks!' (Participant 20, C of E Bishop) and 'I'd say, why me?!' (Participant 15, Catholic Priest). When I probed these comments further, the points I raised at the beginning of this paper were reiterated; i.e. not being an expert in science and the feeling that media interviews tend to reinforce the 'conflict' thesis.

In addition to personal interest as a key finding, another factor was the influence of scientists in clergy's immediate family or social circles. Of the 20 senior church leaders interviewed (minus the 5 that were from science backgrounds themselves) a further 5 reported having someone in their family who was a scientist. The survey responses also showed a statistically significant difference between those who reported themselves as having a close friend or family member who was a scientist and their likelihood of 'disagreeing' or 'strongly disagreeing' with the statement that 'The money spent on sending a spacecraft to Comet 67P should have been spent on providing clean water for people throughout the world'. The 'strongly agree' and 'agree' columns for the Comet 67P statement are predominantly made up of those who do not have members of family or close friends who are scientists, while those at the other end who 'strongly disagree' and 'disagree' are more prevalent among those who do have scientists in their family/social networks. It is important to note, however, that there is still a sizeable chunk in the middle expressing hesitation about the comet statement regardless of whether or not they have family members or close friends who are from a science background. 
Table 3: Crosstabulation on Family/Friend from Science Background and Money Spent on Comet 67P

\begin{tabular}{|c|c|c|c|c|c|c|c|}
\hline & & \multicolumn{5}{|c|}{$\begin{array}{l}\text { The money spent on sending a spacecraft to Comet } 67 \mathrm{P} \text { should have } \\
\text { been spent on providing clean water for people throughout the world }\end{array}$} & \multirow[t]{2}{*}{ Total } \\
\hline & & $\begin{array}{l}\text { Strongly } \\
\text { Agree }\end{array}$ & Agree & $\begin{array}{l}\text { Neither } \\
\text { agree nor } \\
\text { disagree }\end{array}$ & Disagree & $\begin{array}{l}\text { Strongly } \\
\text { disagree }\end{array}$ & \\
\hline \multirow{2}{*}{$\begin{array}{l}\text { Do you have any } \\
\text { family members or } \\
\text { close friends who are } \\
\text { from a science } \\
\text { background? }\end{array}$} & Yes & $7.1 \%$ & $24.6 \%$ & $35.8 \%$ & $28.9 \%$ & $3.5 \%$ & $100.0 \%$ \\
\hline & No & $11.1 \%$ & $27.9 \%$ & $33.9 \%$ & $24.7 \%$ & $2.4 \%$ & $100.0 \%$ \\
\hline \multicolumn{2}{|l|}{ Total } & $8.5 \%$ & $25.8 \%$ & $35.1 \%$ & $27.4 \%$ & $3.2 \%$ & $100.0 \%$ \\
\hline
\end{tabular}

(Reid, 2019: 87)

Such a finding is in keeping with literature on science engagement with Archer et al (2012) noting that 'family habitus' influenced the extent to which science aspirations for teenagers became more 'thinkable' (Archer et al, 2012: 884). Similarly, Scheitle and Ecklund (2017) found that a low level of science interest was the main indicator in religious parents not recommending STEM careers to their children. In addition, Hill's research exploring the persistence of anti-evolution stances over time among young people found that 'social networks play an important moderating role' (Hill, 2014: 575) and are more important than educational attainment. The influence of personal interest was also found to be an important factor in research conducted by Scheitle and Cornell (2015), who found that personal interest in a topic meant that congregation members were more likely to remember it being preached about by their relevant church leaders.

On the whole my research suggests that clergy are indeed enthusiastic, interested, and engaged with science (albeit at a superficial level - in the form of books, documentaries etc). However, as I highlighted earlier, there is a seeming disconnect between levels of enthusiasm/interest in science and subsequent confidence or knowledge in talking about science in the public domain. This hesitation is bound to the points I referenced at the beginning of this article to do with a perceived sense of science as belonging to 'experts' and the prevalence of the conflict thesis in media panels.

\subsection{Relationship between Science and Christianity}


Having already established the level of enthusiasm and interest clergy have towards science, the next connected theme to explore is the way in which clergy view the overarching relationship between science and Christianity. Similar to the discussion on evolution, asking this type of question on a survey is problematic since the way questions are framed impact on the answers selected. Hill raises this point in his discussion on data concerning whether Americans see science and religion in conflict. He found that in surveys such as the Pew Research Centre survey (2014) where participants were offered two answers to choose from (e.g. science and religion 'generally agree' or 'generally conflict') then most select 'generally conflict' (around 59\%). However, when a third possible category is offered (e.g. 'not related to each other in any meaningful way') then only between one-quarter and one-third select the same 'conflict' response (Hill, 2015).

In view of this, the choice of answers I offered when asking how science and Christianity related to each other subsequently took the form of lan Barbour's science and religion typology: 'integration', 'dialogue', 'independence' and 'conflict' (a more detailed discussion of Barbour's typology can be found here: Reid, 2019: 88 ). I also included the additional category of 'other'. In contrast to the findings of the Pew Research Centre survey cited above, I found that $51 \%$ of the clergy I surveyed selected 'integration', followed by 'dialogue' (45\%), 'other' (4\%), 'independence' (0.4\%) and 'conflict' (0.2\%). Based on these percentages, one may be tempted to make the assumption that science and religion are seen by UK clergy as being defined by 'integration' or 'dialogue' rather than that of overwhelming conflict. However, when I asked participants to expand on why they selected their answer, then, something rather more interesting began to happen. The original typology answers did not always match neatly to the reason given for selecting that answer in the first place (for a more detailed discussion see Reid, 2019: 92). For example, although $0.2 \%$ of the sample selected 'conflict' the word 'conflict' - and softer synonyms - were used in the elaboration of how science and religion interact with each other. Furthermore, the science and religion relationship was sometimes unpacked through a number of different components: such as references to 'ethics', 'methodologies/philosophies' and/or 'worldviews'.

\subsection{Compartmentalisation and Ministerial Training}


Interestingly, in the previously mentioned Pew Research Centre survey (2014), 59\% of Americans saw science and religion in conflict, yet, when asked whether science conflicts with their own religious beliefs this reduced to 30\% (Funk and Alper, 2015). In this survey, respondents are making a distinction between how they perceive science and religion more broadly versus their own day-to-day religious beliefs; implying that a process of compartmentalisation is happening when reflecting on where conflict emerges. Also connected to this theme is the way people make sense of science and religion in their own personal lives. In both the interviews from the first phase of ECLAS research (with senior church leaders) and in the second (with church educators) the theme of 'compartmentalisation' emerged. This 'compartmentalisation' occurred in one of two ways: as a strategy for managing personal identities, or as a framework for which to understand science and religion more broadly. In the case of the former, 'compartmentalisation' occurred in those who wanted to keep their scientific and Christian identities separate. In the case of the latter, it was less to do with identity per se and more to do with viewing science and religion as being 'independent' (in keeping with both Barbour's category of 'independence' and Stephen Jay Gould's 'non-overlapping magisteria').

In terms of identity, it has been widely documented that 'compartmentalisation' is used as a strategy for avoiding conflict between religious and other forms of identity such as sexuality (Ganzevoort et al., 2010), sports (Allen-Collinson and Brown, 2012; Stevenson, 1997) or while studying at university (Reid, 2017). In the case of my research, a senior Baptist minister recalled a time when he asked the director of a pharmaceutical company to take part in a question and answer event at his local church. He noted that the scientist was unable to "connect" his professional knowledge of science with his identity as a Christian. He added "I think an awful lot of professional people, not just scientists, leave their professional heads at the door of the church and pick them up when they come back out [...] it's one of the most common complaints of ministers" (Participant 8, Senior Baptist Minister). Similarly participant 6, a Cathedral Dean stated "I saw a lot of scientists who lived their lives in boxes. So faith was here and science was here. I did quite a lot of work to try to get them to bring the two things together". This compartmentalisation also emerged in the form of 'de-skilling' or taking a 'tabula rasa' (Latin phrase often translated as 'blank slate') approach to ordination training. The following interaction illustrates the point further: 
Theological educator 5: I remember going through a process of being de-skilled when I was at theological college and not really understanding why that was happening or...

Interviewer: What do you mean de-skilled?

Theological educator 5: Well it did feel as though, you had a whole bunch of people coming from various backgrounds, and it felt as though whatever you were, whether you were a teacher, a nurse, a doctor or a lawyer or whatever; it felt as though all your previous experience was never even referred to, and there was no place for it to be acknowledged or used in the learning community. I remember experiencing that and thinking how odd it felt, how slightly humiliating it felt [...] I still think we are not very good at acknowledging how somebody's existing educational role relates to their training and their formation for ministry.

While I encountered this particular narrative, I did also come across educators who were taking active steps to encourage ordinands to take an integrated approach to their identities. Participant 7 provided a particularly passionate account of this:

Interviewer: Can you tell me a bit more about what the tabula rasa approach is?

Theological educator 7: When somebody goes to college, all their previous experience is ignored, they are effectively deskilled and then through a psychological process they are kind of built up as a minister. And actually I think that is incredibly damaging and abusive so I won't go along with that. So I encourage people, particularly if they are self-supporting and they are working in a secular field like say [the] scientific field and many of them are as leaders like the professor I mentioned. I encourage them to draw on their experience in the widest possible sense to, in their assessment to show that they engaged in their formation right across the board. That is not always possible because there is a tendency for the curates to be focused on the parish ministry that they are doing and they think, oh it is so exciting, it is new, I want to really get on with this and for a while they don't make connections but then neither do they make connections with the formal theology that they have done before they were ordained. So our job is to help them in that integrative process so that all of life and all of learning becomes 
one whole which is slow and probably doesn't happen in the two or three years, well three or four years we have them.

Also connected to this idea of compartmentalisation was the dominance of the humanities both in terms of the framing/shaping of teaching and also in the backgrounds of people who train for ordination. A particularly interesting example of this was a passage from one interviewee reflecting on a conversation they had had with a student. This student was from a science background and was complaining about how difficult it was to switch into a different mode of thinking for his ordination training, participant 11 elaborates;

He was a microbiologist by training, very well qualified, had been working for multinationals and projects leading [...] that kind of stuff, and he was just venting his frustration because he said: "I am a scientist, I go into a lab and I think I know something, and I do an experiment, and then I really think I know something, and then I do the experiment again, and, I know, I know something. And he said, [in] Theology Barth says this, Brueggemann says this, Brunner says this, urgh. And I said, welcome to the humanities. You know and a lot of it is about paradigms of knowledge, and what is valid, and what do we know, and the difference, in that [...] Theology is, in one sense, not empirical. (Theological educator 11)

Participant 11 was the only church educator to emphasise the point that natural scientists might struggle more to adapt to the 'paradigms of knowledge' required for ordination training. However, the distinction between the humanities and sciences was also a phenomenon I encountered in the first phase of ECLAS research with senior church leaders. During the recruitment of participants a Church of England bishop declined to be interviewed based on having been "educated in the world of 'two cultures'". This was a reference to a famous Rede lecture given by C. P. Snow in 1959 at Cambridge University where he stated that "the intellectual life of the whole of Western society is increasingly being split into two polar groups... at one pole we have the literary intellectuals...at the other scientists" (Snow, 1959: 4). His thesis has become shorthand for a split between the humanities and natural sciences with a tendency for students and academics to remain isolated in their relevant subject areas. It is clear that the bishop was referring to himself as someone who belonged to the humanities or literary sphere and as a result did not feel able competent to take part in the interview. Crucially, however, C.P Snow himself was a scientist and writer, and his lecture aimed to highlight and challenge this separation 
of academic spheres; whereas the bishop was using it to justify his own non-participation in the interviews.

Interestingly, several interviewees raised the importance of ordination training taking a genuinely 'interdisciplinary' approach and, if this was fully endorsed, then separate paradigms of learning would be less of an issue. However, when asked which aspects of science ought to be taught on the syllabus, participants overwhelmingly suggested the 'philosophy of science' and (a much smaller number) the 'methodology of science'. The former is arguably an extension of the humanities approach but the latter could open discussion from both a humanities and science perspective.

\section{Moving beyond 'fear' reflections from cosmologist and theologian - Revd Professor David Wilkinson}

The data presented in this paper resonates strongly with the experience of those of us who have been working, in the terminology of Ecklund, as 'boundary pioneers', navigating the academic terrain of science and theology (Ecklund, 2010: 46). A significant feature of this boundary has been a number of scientists who have become professional theologians (e.g. Polkinghorne, 1996), on-going professional scientists who have contributed to taking the nature of theology seriously (e.g. McLeish, 2014) and celebrity scientists who have raised theological questions within public discourse (e.g. Giberson and Artigas 2007).

While the quality of theological engagement has varied, the work of Hawking and Dawkins in particular has fuelled popular interest in the big questions of science and religion both inside and beyond faith communities (Wilkinson, 2019). Best-selling books, television series, podcasts, live shows and debates, and even biographical movies such as The Theory of Everything have begun to break down the two cultures approach and renewed a confidence in science which was questioned by the growth of post-modernity (Alexander, 2005). Therefore, it is not a surprise to learn about the high level of enthusiasm and engagement in general by clergy concerning science. Yet the conflict model underlies the approach of Hawking and Dawkins and is attractive to media producers who believe that controversy leads to viewing figures and sales. Here the contrast in the nature of the boundary between the academy and the public sphere could not be sharper. The conflict model has long been dismissed by historians of science (Harrison, 2015) but remains embedded in the media and at certain level of primary and secondary education (Astley and Francis, 2010). 
The temptation, in order to avoid the conflict model, is to adopt compartmentalisation. The motivation for Gould's NOMA model was to avoid the clash of science and religion within the public sphere of US education but the research presented here shows a similar temptation within UK church leadership. As I suggested in an earlier paper, the adoption of a how/why distinction between science and religion appears to be an avoidance strategy by some church leaders (Bouveng and Wilkinson 2016). It avoids any difficult questions being posed by science to religious belief and may ensure that theologians and church leaders retain authority in religious belief.

The fear shown by church leaders in addressing publicly the claims of science is therefore at many levels. Fear stemming from lack of knowledge of science may be coupled with a lack of knowledge of scientists themselves. Science is a human activity and can only be understood with reference to beliefs, values and personalities of professional scientists. The stubborn existence of the conflict model alongside its use in public discourse by celebrity scientists puts church leaders immediately into a defensive posture not only in truth claims but also in a sense of status within culture.

The questions that this raises for the training and formation of church leaders are profound. First, how do theological educators affirm science as a gift from God and affirm both the students' enthusiasm for and engagement with science? This means the valuing of the skills and expertise of the person who has already worked in science while taking seriously the support needed to ultilise such gifts within a different academic discipline. This can be done in a number of ways in the curriculum and we will come on to this in a moment. However, we should not neglect the power of senior church leaders modelling an engagement with science which is not characterised by fear. Fear and hesitancy about science from senior church leaders has a trickle-down effect eroding confidence in clergy and laity. Second, how do theological courses engage science? Perhaps the worst thing is to put these issues into a silo of a course in science and religion taught by specialists for those who are already interested in the subject. Rather can teachers engage science within the classic disciplines of theology, showing its relevance to church history, philosophical theology, systematics, ethics and biblical studies? But science engaged theology is more than just content translated to the church leader in training by a sympathetic Christian theologian. Science engaged theology is about theologians engaging in authentic dialogue with scientists. This will mean the invitation of scientists into the classroom of the seminary or course, with the 
attendant risk that some will represent conflict or compartmentalisation as well as dialogue. Third, how do theologians see God at work outside of the church in creation, redemption and in the work of the Spirit. It is a lack of this theological vision that engenders fear, insularity and an attempt to hold onto authority by the church. Overcoming fear can be replaced by an expectancy that God is at work at the boundary and a humility that we do not know and do not need to know all of the answers. The skill of a theologian and indeed a scientist is to be able to discover the right questions.

\section{Conclusion}

The aim of the research reported in this paper has been to provide a snapshot of how clergy and church educators understand the relationship between science and religion against the backdrop of popular media's tendency to portray science and religion as being in conflict. One of the key observations to emerge has been that despite the relationship between science and religion being framed as one of 'conflict' in the media, this was not the prevalent view among the church leaders and educators I surveyed and interviewed. Indeed, many church leaders were enthusiastic and complimentary about science; viewing the relationship as one of 'integration' or 'dialogue'. Nevertheless, the conflict thesis had framed the way in which church leaders related to science - with expressions of fear and uncertainty being reported by church leaders, and in the clear omission of science topics in ordination training in a UK context.

There is a clear discrepancy between the degree of enthusiasm reported by church leaders and their subsequent hesitation or fear in talking about science in the public domain. One of the potential key drivers in shaping how clergy view science and religion can be found in ordination training. However, as demonstrated by the mention of the 'tabula rasa approach', such an approach can lead to theological training not being able to subsume or contextualise previous scientific knowledge. Instead, the tabula rasa approach silently implies the irrelevance of science thereby allowing existing stereotypes to persist. In view of the latter, Wilkinson's contribution as a theologian and scientist goes one step further in asking the reader: what should theological and scientific engagement look like? It is only in beginning to take this question seriously, (alongside engagement with scientists, theologians and educators) that clergy will begin to have the tools to comfortably engage with science and religion in the public domain. 


\section{Bibliography}

Allen-Collinson, J., Brown, R. (2012) 'I'm a Reddie and a Christian! Identity negotiations amongst first-year university students', Studies in Higher Education, 37:4, 497-511

Alexander, D. (2005) Can We Be Sure About Anything?: Science, Faith and Postmodernism, Nottingham: Apollos.

Archer, L. DeWitt, J. Osbourne, J. Dillon, J. Willis, B. Wong, B. (2012) 'Science aspirations, capital, and family habitus: How families shape children's engagement and identification with science', American Educational Research Journal, 49(5): 881-908.

Astley, J and Leslie, F. (2010) 'Promoting positive attitudes towards science and religion among sixth-form pupils: dealing with scientism and creationism'. British Journal of Religious Education, Vol.32 (No.3). pp. 189-200.

Baker, J. (2012) 'Public perceptions of incompatibility between science and religion', Public Understanding of Science, 21(3): 340-353.

Bio Logos Barna Survey (2012) Survey on Clergy and their views towards Creation. https://biologos.org/blogs/guest/a-survey-of-clergy-and-their-views-on-origins.

Barbour, I. (2000) When science meets religion: Enemies, strangers or partners? London: SPCK.

Bouveng, R. and Wilkinson, D. (2016) 'Going beyond the how and why of sciencereligion? Senior Christian leaders on science and personal faith', Science and Christian Belief, 28(2): 100-115.

Carlisle, J., Hameed, S. and Elsdon-Baker, F. 'Muslim Perceptions of Biological Evolution: A Critical Review of Quantitative and Qualitative Research'. In Science, Belief and Society: International Perspectives on Religion, Non-Religion and the Public Understanding of Science, ed. by Jones, S., Kaden, T., Catto, R. Policy Press: Bristol. 
Colburn, A. and Henriques, L. (2006) 'Clergy views on evolution, creationism, science and religion', Journal of Research in Science Teaching, 43(4): 419-442.

Dickerson, D. Dawkins, K. Penick, J. (2008) 'Clergy's views of the relationship between science and religious faith and the implications for science education', Science and Education, 17(4): 359-286.

Ecklund, E. (2010) Science vs. religion: What scientists really think, New York: Oxford University Press.

Ecklund, E. Sorrell, K. Park, J. (2011) 'Scientists negotiate boundaries between religion and science', Journal for the Scientific Study of Religion, 50(3): 552-569.

Elsdon-Baker, 'Questioning evolution is neither science denial nor the preserve of creationists', The Guardian, 5 September 2017.

Elsdon-Baker, F. Leicht, C. Mason-Wilkes, W. Preece, E. Piggott, L. (2017) 'Summary report of preliminary findings for a survey of public perspectives on Evolution and the relationship between evolutionary science and religion', https://sciencereligionspectrum.org/wp-content/uploads/2017/09/SRESYouGov-surveypreliminary-findings-5.9.17.pdf [accessed 14 April 2018].

Elsdon-Baker, F. (2015) 'Creating creationists: The influence of 'issues framing' on our understanding of public perceptions of clash narratives between evolutionary science and belief', Public Understanding of Science, 24(4): 422-439.

Evans, J. and Evans, M. (2008) 'Religion and science: Beyond the epistemological conflict narrative', Annual Review of Sociology, 34: 87-105.

Evans, J. (2011) 'Epistemological and moral conflict between religion and science', Journal for the Scientific Study of Religion, 50(4): 707-727.

Funk, C., Alper, B. 'Perception of conflict between science and religion', Pew Research Center, http://www.pewinternet.org/2015/10/22/perception-of-conflict-between-scienceand-religion/ [accessed 16 April 2018]. 
Giberson, K and Artigas, M. (2007) Oracles of Science. New York, NY: Oxford University Press.

Gould, S. (1997) 'Non-overlapping magisteria', Natural History, 106(2).

Gregory, D. (2017) 'Do science and Baptists mix?' Baptist Ministers Journal, 336: 5-11.

Harrison, P. (2015) The Territories of Science and Religion. London and Chicago: University of Chicago Press.

Harrold, F. Eve, R. Taylor, J. (2004) 'Creationism, American-style: Ideology, tactics and rhetoric in a social movement', in S. Coleman and L. Carlin (eds) The Cultures of Creationism, Aldershot: Ashgate, pp 67-85.

Hill, J. (2014) 'Rejecting evolution: The role of religion, education, and social networks', Journal for the Scientific Study of Religion, 53(3): 575-594.

Hill, J. (2015) 'Do Americans believe science and religion are in conflict?' https://www.bigquestionsonline.com/2015/04/06/americans-believe-science-religion-areconflict/ [accessed 16 April 2018].

Kind, S. (2019) 'Avoiding the 'Anti-intellectual Abyss': How Secular Humanists in Sweden try to

Define the Boundaries between Science, Religion, Pseudoscience and Postmodernism'. In Jones, S., Kaden, T., Catto, R. (eds) Science, Belief and Society: International Perspectives on Religion, Non-Religion and the Public Understanding of Science. Bristol University Press.

Jones, S., Kaden, T., Catto, R. (eds) Science, Belief and Society: International Perspectives on Religion, Non-Religion and the Public Understanding of Science. Bristol University Press.

Lee, L. (2019) 'Feeling Raional: affinity and Affinity Narratives in British Science-Nonreligion Relations'. In Jones, S., Kaden, T., Catto, R. (eds) Science, Belief and Society: 
International Perspectives on Religion, Non-Religion and the Public Understanding of Science. Bristol University Press.

Lewis-Beck, M. S., Bryman, A., Liao, T. F. (2003). The Sage Encyclopedia of Social Science Research Methods. Thousand Oaks, California: Sage.

Mathieson, K. 'Rebranding science so it is seen by all people as a fundamental and inclusive part of our society', LSE Impact Blog, http://blogs.Ise.ac.uk/impactofsocialsciences/2017/11/15/rebranding-science-so-it-isseen-by-all-people-as-a-fundamental-and-inclusive-part-of-our-society/ [accessed 16 April 2018].

McLeish, T. (2014) Faith and Wisdom in Science, Oxford: Open University Press.

Polkinghorne, J. (1995) Serious Talk: Science and Religion in Dialogue, A\&C Black.

Reid, L. (2017) How Religious Students Negotiate the Secular Culture of a State University: A Sociological Study of the University of Manchester. Lampeter: Mellen Press.

Reid, L. (2019) 'Researching clergy attitudes towards science: a reflective account of key methodological challenges'. In Jones, S., Kaden, T., Catto, R. (eds) Science, Belief and Society: International Perspectives on Religion, Non-Religion and the Public Understanding of Science. Bristol University Press.

Rockliffe, L., Chorley, A., Marlow, L., Forster, A. (2018) 'It's hard to reach the "hard-toreach": the challenges of recruiting people who do not access preventative healthcare services into interview studies', International Journal of Qualitative Studies on Health and Well-being, 13:1.

R.R. Ganzevoort, M. van der Laan \& E. Olsman (2011) Growing up gay and religious. Conflict, dialogue, and religious identity strategies, Mental Health, Religion \& Culture, 14:3, 209-222,

Scheitle, C., Ecklund, E. (2017) 'Recommending a child enter a STEM career: The role of religion', Journal of Career Development, 44(3): 251-256. 
Scheitle, C., Cornell, N. (2015) 'Hearing clergy speak about social and political issues: Examining the effects of religious tradition and personal interest', Social Science Quarterly, 96(1): 148-160.

Scheitle, C. (2011) 'US college students' perception of religion and science: Conflict, collaboration, or independence? a research note', Journal for the Scientific Study of Religion, 50(1): 175-186.

Snow, C. (2012) 'The Rede lecture, (1959)' in C. Snow and S. Collini (eds) The Two Cultures: And a Second Look, Cambridge: Cambridge University Press, pp 1-22.

Stevenson, C. L. (1997). 'Christian Athletes and the Culture of Elite Sport: Dilemmas and Solutions', Sociology of Sport Journal, 14(3), 241-262.

Unsworth, A. (2019) 'Discourses on Science and Islam: A View from Britain' in Jones, S., Kaden, T., Catto, R. (eds) Science, Belief and Society: International Perspectives on Religion, Non-Religion and the Public Understanding of Science. Bristol University Press.

Unsworth, A and Voas, D (2018) Attitudes to evolution among Christians, Muslims and the Non-Religious in Britain: Differential effects of religious and educational factors, Public Understanding of Science, 27(1), 76-93.

Wilkinson, D. A. (2020) 'Pop science and pop theology: new ways of exploring an old dialogue', Theology, 123(1), pp. 20-27 